\title{
In Vivo Effect of Pituitary Adenylate Cyclase Activating Polypeptide 38 (PACAP 38) on the Secretion of Luteinizing Hormone (LH) in Male Rats
}

\author{
Yutaka OSUGA, Naoki MITSUHASHI and Masahiko MIZUNO \\ Department of Obstetrics and Gynecology, Faculty of Medicine, \\ University of Tokyo, Tokyo 113, Japan
}

\begin{abstract}
In view of the recent demonstrations that pituitary adenylate cyclase activating polypeptide (PACAP) 38 stimulates the release of LH from superfused pituitary cells and that the hypothalamus and anterior pituitary have highly selective binding sites for the peptide, we have surveyed the effect of intraatrial injections of PACAP 38 and vasoactive intestinal peptide (VIP), which has $68 \%$ homology with PACAP 38, in intact adult male rats. Furthermore the effect of intracerebroventricular (icv) injectioin of PACAP 38 was investigated. Intraatrial $(10,30,100 \mu \mathrm{g})$ and icv $(8,32 \mu \mathrm{g})$ administration of PACAP 38 stimulated LH release significantly $(P<0.01)$ in a dose-related fashion. Icv injection at a dose of $0.8 \mu \mathrm{g}$ was ineffective. The time course pattern of $\mathrm{LH}$ release by intraatrial injection and that by icv injection was similar, but the LH levels increased by intraatrial injection were much higher than that by icv injection. Intraatrial administration of VIP had almost no effect on LH release. These findings suggested that PACAP 38 stimulates LH release in vivo.
\end{abstract}

Key words: PACAP, in vivo, VIP, LH.

(Endocrinol Japon 39: 153-156, 1992)

PITUITARY adenylate cyclase activating polypeptide with 38 residues (PACAP 38) and the shorter peptide, PACAP 27, with its first 27 residues identical to PACAP 38 were isolated from the ovine hypothalamus in recent years $[1,2]$. The molecular cloning and characterization of cDNAs for the precursor of PACAP 38 from ovine hypothalamus, human testis [3] and rat brain [4] showed that the amino acid sequences were completely identical. PACAP stimulates adenylate cyclase activity in rat pituitary cells [1], PC12 cells [5] and rat pancreatic acinar cell line [6]. PACAP also stimulates the release of GH, PRL, ACTH and LH in the superfused rat pituitary cells [1]. On the other hand, the in vivo effect of PACAP 38 is unknown. The location of PACAP was demons-

Received: September 1991

Accepted: January 17, 1992

Correspondence to: Dr. Yutaka OSUGA, Department of Obstetrics and Gynecology, Faculty of Medicine, University of Tokyo, 7-3-1 Hongo, Bunkyo-ku, Tokyo 113, Japan. trated immunohistochemically in the ovine brain and posterior pituitary [7]. The binding sites for PACAP were characterized in several tissues [8, 9], cultured astrocytes [10] and splenocytes [11]. In particular, in membranes from the hypothalamus, anterior pituitary, and cultured astrocytes binding sites are densely located [8, 10]. These findings suggest that PACAP has some effect on the hypothalamus or pituitary in vivo.

On the other hand vasoactive intestinal peptide (VIP), which has $68 \%$ homology on the amino acid sequence with PACAP 38, has been demonstrated to suppress the plasma concentration of LH by intracerebroventricular (icv) injection in ovariectomized rats $[12,13]$. These findings prompted us to investigate whether PACAP 38 has any effect on the release of $\mathrm{LH}$ in vivo.

\section{Materials and Methods}

Adult male Wistar rats about $250 \mathrm{~g}$ were used. 
The rats had free access to laboratory chow and water. PACAP 38 and VIP were obtained from the Peptide Institute Inc. (Osaka, Japan).

\section{Exp 1: effects of intraatrial injection of PACAP 38 and} VIP

The rats were lightly anesthetized and an intraatrial cannula was placed via the jugular vein. On the following day the intraatrial cannula was attached to a length of polyethylene tubing to allow withdrawal of blood from conscious, freely moving rats. Blood samples $(800 \mu l)$ were withdrawn before and at 10,20,30 and $60 \mathrm{~min}$ after the injection of PACAP 38 or VIP in saline or saline alone $(100 \mu l)$. The blood samples were centrifuged, and the separated plasma was kept frozen until assayed for LH.

\section{Exp 2: effect of icv injection of PACAP 38}

Rats anesthetized with pentobarbital had an icv cannula stereotaxically implanted in the lateral ventricle of the brain. After a week of recovery from the surgery, an intraatrial cannula was implanted as described above. On the following day the rats were given an intracerebroventricular injection of PACAP 38 diluted in $8 \mu l$ saline. Control rats received an icv injection of $8 \mu l$ saline. Blood samples were obtained as in $\operatorname{Exp} 1$. At the end of the experiment, proper placement of the icv cannulas was checked by an injection of $8 \mu l$ blue dye. Only data for those rats showing delivery of the dye to the ventricles were included in the statistical analysis of the results.

\section{Hormone analysis}

Plasma LH levels were measured by the double antibody RIA method with materials provided by the National Pituitary and Hormone Distribution Program of the NIDDK. The standard preparation was LH RP-2.

\section{Statistical analysis}

The data were expressed as the mean \pm SEM. Student's paired $t$-test was used for statistical analysis.

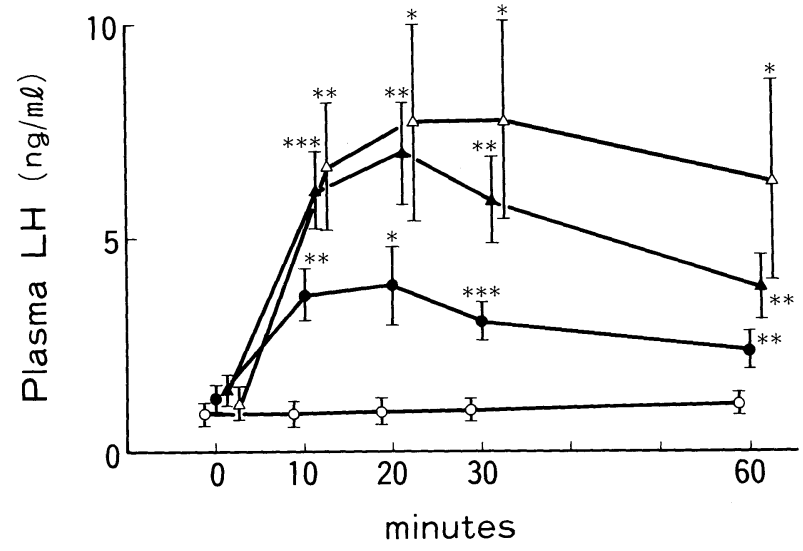

Fig. 1. The effect of intraatrial injection of PACAP 38. Each point represents the mean \pm SEM for six or seven animals. Injected PACAP 38 in $100 \mu l$ saline was $100 \mu \mathrm{g}$ $(\triangle), 30 \mu \mathrm{g}(\mathbf{\Delta}), 10 \mu \mathrm{g}(\mathbf{\bigcirc}), 0 \mu \mathrm{g}(\bigcirc) . *, P<0.05$; **, $P<0.01 ; * * *, P<0.001$ vs. pre-injection levels.

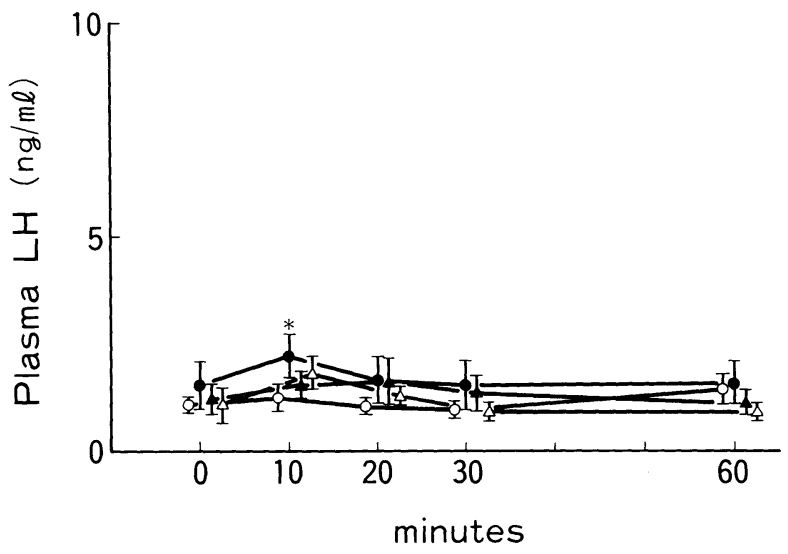

Fig. 2. The effect of intraatrial injection of VIP. Each point represents the mean \pm SEM for six animals. Injected VIP in $100 \mu l$ saline was $100 \mu \mathrm{g}(\triangle), 30 \mu \mathrm{g}(\mathbf{\Delta}), 10 \mu \mathrm{g}$ $(\bigcirc), 0 \mu \mathrm{g}(\bigcirc) . *, P<0.05$ vs. pre-injection levels.

\section{Results}

The effects of intraatrial injection of PACAP 38 on $\mathrm{LH}$ release in male rats are depicted in Fig. 1. All of the three doses tested were effective in stimulating $\mathrm{LH}$ release. At a dose of $10 \mu \mathrm{g}$ a significant LH increase was evoked at 10, 20, 30 and $60 \mathrm{~min}$. The higher doses of $30 \mu \mathrm{g}$ and $100 \mu \mathrm{g}$ evoked a much greater increase in LH at every point of time. The styles of the time course are similar for all three doses, and the peak level of LH was observed at $20 \mathrm{~min}$ at doses of 10 and 30 $\mu \mathrm{g}$.

The effect of intraatrial injection of VIP on LH release is shown in Fig. 2. Of the various doses of 


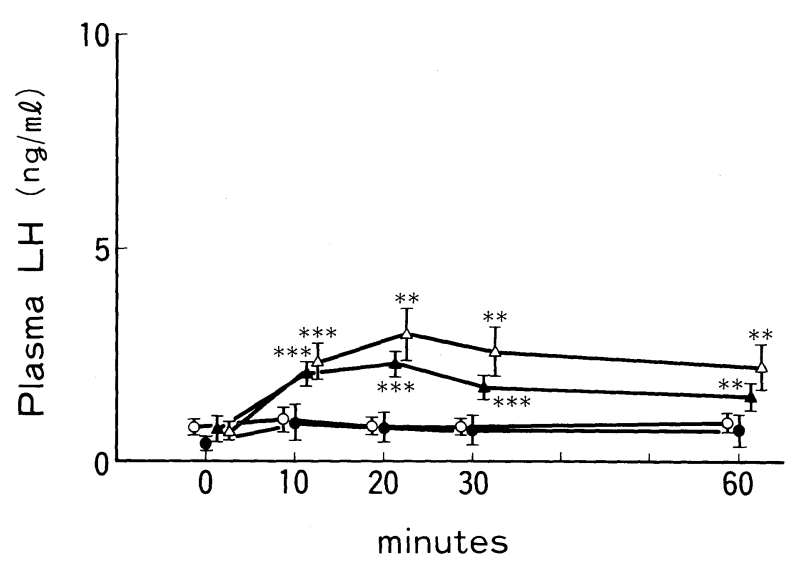

Fig. 3. The effect of intracerebroventricular injection of PACAP 38. Each point represents the mean \pm SEM for seven to thirteen animals. Injected PACAP 38 in $8 \mu l$ saline was $32 \mu \mathrm{g}(\triangle), 8 \mu \mathrm{g}(\mathbf{\Delta}), 0.8 \mu \mathrm{g}(\mathbf{\bullet}), 0 \mu \mathrm{g}$ (○). **, $P<0.01$; ${ }^{* * *}, \mathrm{p}<0.001$ vs. pre-injection levels.

VIP tested $10 \mu \mathrm{g} \mathrm{VIP} /$ rat stimulated a significant increase in plasma $\mathrm{LH}(0.01<P<0.05)$ at $10 \mathrm{~min}$ only. But the increase is small compared with that evoked by PACAP 38. LH levels showed no significant increase at doses of $30 \mu \mathrm{g}$ and $100 \mu \mathrm{g}$ of VIP.

The effect of icv injection of PACAP 38 is shown in Fig. 3. At doses of $8 \mu \mathrm{g}$ and $32 \mu \mathrm{g}$ a significant increase in LH was observed at 10,20,30 and 60 min. The time course is similar to that following intraatrial injection and the peak level of $\mathrm{LH}$ was also observed at $20 \mathrm{~min}$. The lower dose of $0.8 \mu \mathrm{g}$ did not result in a significant increase in $\mathrm{LH}$.

\section{Discussion}

The present study demonstrated that PACAP 38 stimulated the release of $\mathrm{LH}$ in the adult male rat in vivo. On the other hand intraatrial injection of VIP had almost no effect on the release of $\mathrm{LH}$ at the same dose at which PACAP 38 stimulated LH release in the adult male rat. In cultured murine splenocytes, PACAP 38 and PACAP 27 were reported to inhibit concanavalin A-induced prolif- eration in the same dose-dependent manner as VIP. Scatchard analysis indicated that cultured murine splenocyte has type 2 PACAP binding site [11], to which PACAP and VIP bind with similar affinities [9]. In this case it is suggested that the action of PACAP is mediated by a similar or the identical site used by VIP. The hypothalamus and anterior pituitary are reported to have type 1 PACAP-binding sites, which have greater affinity for PACAP than for VIP [11]. Thus there is the possibility that the LH releasing effect of PACAP 38 is mediated by type 1 PACAP-binding sites.

Icv injection of VIP has been reported to suppress the release of LH in the ovariectomized rat $[12,13]$. In this study intraatrial injection of VIP had almost no effect. Although the exact reason is unknown, it may be due to the difference of the sex of the rat used or the difference in the injection site.

An immunohistochemical study demonstrated that there is a PACAP immunoreactive fiber network in both external and internal zones of the median eminence and pituitary stalk, and the fibers are in close contact with the hypophysial portal capillaries [5]. Therefore PACAP 38 may be released in the hypophysial portal capillaries and act on the anterior pituitary. On the other hand there is also the possibility that PACAP 38 may have some effect on the median eminence itself. In the present study an icv injection of PACAP 38 stimulated the release of $\mathrm{LH}$ at a dose of more than $8 \mu \mathrm{g}$. However, an intraatrial injection of PACAP 38 evoked LH release much more than an icv injection at almost the same dose. These data suggest that the LH releasing effect of PACAP 38 may be more potent via the anterior pituitary than via the hypothalamus. Whether the LH releasing effect of PACAP 38 in vivo is physiological action or not remains to be investigated. For this purpose the concentrations of PACAP 38 in the hypophysial portal capillary blood and in the peripheral blood must be elucidated.

\section{References}

1. Miyata A, Arimura A, Dahl R, Minamino N, Uehara A, Jiang L, Culler MD, Coy DH (1989) Isolation of novel 38 residue-hypothalamic polypeptide which stimulates adenylate cyclase in pituitary cells. Biochem Biophys Res Commun 164: 567-574.

2. Miyata A, Jiang L, Dahl R, Kitada C, Kubo K, Fujino M, Minamino N, Arimura A (1990) Isola- 
tion of a neuropeptide corresponding to the $\mathrm{N}$-terminal 27 residues of the pituitary adenylate cyclase activating polypeptide with 38 residues (PACAP 38). Biochem Biophys Res Commun 170: 643-648.

3. Kimura C, Ohkubo S, Ogi K, Hosoya M, Itoh Y, Onda H, Miyata A, Jiang L, Dahl R, Stibbs H, Arimura A, Fujino M (1990) A novel peptide which stimulates adenylate cyclase: Molecular cloning and characterization of the ovine and human cDNAs. Biochem Biophys Res Commun 164: 567-574.

4. Ogi K, Kimura C, Onda H, Arimura A, Fujino M (1990) Molecular cloning and characterization of cDNA for the precursor of rat pituitary adenylate cyclase activating polypeptide (PACAP). Biochem Biophys Res Commun 173: 1271-1279.

5. Watanabe T, Ohtaki T, Kitada C, Tsuda M, Fujino M (1990) Adrenal pheochromocytoma PC12h cells respond to pituitary adenylate cyclase activating polypeptide. Biochem Biophys Res Commun 173: 252-258.

6. Buscail L, Gourlet P, Cauvin A, Neef P, Gossen D, Arimura A, Miyata A, Coy DH, ,Robberecht P, Christophe J (1990) Presence of highly selective receptors for PACAP (pituitary adenylate cyclase activating peptide) in membranes from the rat pancreatic acinar cell line AR 4-2J. FEBS lett. 262: $77-81$.

7. Köves K, Arimura A, Somogyvari-vigh A, Vigh S, Miller J (1990) Immunohistochemical demonstration of a novel hypothalamic peptide, pituitary adenylate cyclase activating polypeptide, in the ovine hypothalamus. Endocrinology 127: 264-271.
8. Gottschall PE, Tatsuno I, Miyata A, Arimura A (1990) Characterization and distribution of binding sites for the hypothalamic peptide, pituitary adenylate cyclase activating polypeptide. Endocrinology 127: 272-277.

9. Shivers BD, Gorcs TJ, Gottschall PE, Arimura A (1991) Two high affinity binding sites for pituitary adenylate cyclase-activating polypeptide have different tissue distributions. Endocrinology 128: 3055-3065.

10. Tatsuno I, Gottschall PE, Köves K, Arimura A (1990) Demonstration of specific binding sites for pituitary adenylate cyclase activating polypeptide (PACAP) in rat astrocytes. Biochem Biophys Res Commun 168: 1027-1033.

11. Tatsuno I, Gottschall PE, Arimura A (1991) Inhibition of mitogen-stimulated proliferation of murine splenocytes by a novel neuropeptide, pituitary adenylate cyclase activating polypeptide: a comparative study with vasoactive intestinal peptide. Endocrinology 128: 728-734.

12. Alexander MJ, Clifton DK, Steiner RA (1985) Vasoactive intestinal peptide effects a central inhibition of pulsatile luteinizing hormone secretion in ovariectomized rats. Endocrinology 117: 2134-2139.

13. Stobie KM, Weick RF (1990) Effects of lesions of the suprachiasmatic and paraventricular nuclei on the inhibition of pulsatile luteinizing hormone release by exogenous vasoactive intestinal peptide in the ovariectomized rat. Neuroendocrinology 51: 649-657. 